\title{
O ensino da avaliação de redações escolares a partir do léxico
}

\author{
Teaching the evaluation of school essays based on the lexicon
}

Márcia Sipavicius SEIDE*

\begin{abstract}
RESUMO: Pesquisa fomentada pela Unesco (ATORRESI et. al., 2010) indicou que redações escolares produzidas por alunos brasileiros apresentam um nível elevado de falhas por inadequação lexical. Análise de redações produzidas por alunos da região oeste do estado do Paraná corroborou o resultado da pesquisa prévia da Unesco (SEIDE; DURÃO, 2016). Para melhor compreensão deste problema, foi realizada uma oficina de correção textual em 2014 com alunos e ex-alunos de um curso de Licenciatura em Letras de uma universidade pública da região. Os dados mostraram que o componente lexical foi subnotificado pelos participantes, isto é, muitas inadequações lexicais não foram sequer percebidas. Análise posterior do currículo do curso revelou que o componente lexical não era ensinado como um dos critérios de correção textual. Tendo isto em vista, foi elaborado e aplicado, na disciplina de Lexicologia da Língua Portuguesa, um módulo didático baseado na Abordagem Lexical (LEWIS, 2002) no primeiro semestre de 2019 no quarto ano da licenciatura da mesma universidade na qual foi feita a oficina em 2014. Os resultados obtidos mediante comparação das avaliações de duas redações escolares feitas pelas alunas da disciplina mostra que, na média, a percepção

ABSTRACT: Research sponsored by UNESCO have shown that school essays written by Brazilian students present a high level of failures due to lexical inadequacy (ATORRESI et. al., 2010). Analysis of essays produced by students from the western region of the state of Paraná corroborated the results of UNESCO previous research. For a better understanding of this problem, results of a workshop of textual correction in 2014 with students and alumni of undergraduate course of teacher training on Languages of a public university in this region were investigated. The data showed that the lexical component was underreported by the participants, as several unsuitable lexical choices were not even perceived. Later analysis of the curriculum of the undergraduate course of Language Teaching training revealed that the lexical component was not taught as one of the criteria of textual correction. Having this in view, in the first semester of 2019, to students of the fourth year of the mentioned undergraduate course held in 2014, a didactic module based on the Lexical Approach was elaborated and applied in the subject of Lexicology of Portuguese Language. The results obtained by comparing the evaluations of two essays by the students of the subject show that, on average, the
\end{abstract}

\footnotetext{
* Doutorado em Letras, Universidade Estadual do Oeste do Paraná. ORCID: https://orcid.org/0000-00032859-1749. marcia.seide@unioeste.br.
} 
tanto de blocos bem formados (combinações lexicais que o uso tornou convencionais) quanto de blocos mal formados (combinações lexicais não convencionais) dobrou ao final do módulo. Isto significa que a aplicação do módulo didático foi capaz de aumentar a percepção e a avaliação do uso de blocos de palavras em redações escolares por parte das alunas que participaram do módulo.

PALAVRAS-CHAVE: Abordagem lexical. Ensino do léxico. Língua portuguesa. Língua materna. Avaliação de redação escolar. perception of both well-formed blocks (lexical combinations conventionalized by usage) and poorly formed blocks (unconventional lexical combinations) doubled at the end of the module. It means that the application of the didactic module was able to increase perception and evaluation of the use of chunks of words in student essays by the students that participated in the module.

KEYWORDS: Lexical approach. Lexicon teaching. Portuguese language. Mother tongue. School essays evaluation.

\section{Introdução}

Em 2010 a Unesco publicou, em língua espanhola, os resultados de uma pesquisa realizada em países da América Latina e do Caribe1 sobre as habilidades de escrita dos alunos a partir da análise de redações escolares escritas por estudantes que cursavam séries correspondentes ao 3. e ao 6.ํanos do Ensino Fundamental brasileiro (ATORRESI et al., 2010). Em cada país, foi aplicada uma proposta de redação a uma amostra de alunos de cada ano de escolaridade. As redações assim produzidas foram avaliadas sob vários aspectos, entre eles, o uso adequado de vocabulário. Verificou-se a quantidade de inadequação vocabular presente nos textos, e se investigou a causa das inadequações. As redações brasileiras apresentaram um porcentual superior à média neste quesito (ATORRESI et al., 2010).

A análise de outro corpus de redações escolares apontou resultado semelhante. Foram analisadas 35 redações produzidas por alunos matriculados no último ano do

\footnotetext{
${ }^{1}$ A saber: Argentina, Brasil (especificamente na cidade de São Paulo), Colômbia, Cuba, Chile, Equador, El Salvador, Guatemala, México (especificamente no estado de Nuevo León), Nicarágua, Panamá, Paraguai, República Dominicana e Uruguai.
} 
ensino fundamental (atual 9. ano) e do primeiro do ensino médio de uma escola pública do município de Cascavel, no oeste do estado do Paraná. Essas redações foram produzidas como parte de um projeto de intervenção pedagógica na escola proposto e desenvolvido por professores e alunos do Programa de Pós-Graduação em Letras da Unioeste entre 2011 e 2013. Em 21 das redações avaliadas, houve ocorrência de inadequação vocabular (SEIDE, 2015; DURÃO; SEIDE, 2016). Cumpre esclarecer que nesse estudo e neste artigo, considera-se que a inadequação vocabular é o resultado do "emprego de uma palavra num contexto impróprio, resultando numa sequência de palavras <<desajeitada >>" (OLIVEIRA, 2006, p. 50). Como exemplos de inadequação vocabular, podem-se citar o emprego do substantivo "consumista" e de sua combinação com o adjetivo "consciente" numa redação escolar da qual, pela proposta de redação que motivou a produção textual, se esperava que o aluno se posicionasse contrariamente ao consumismo e aos excessos de propaganda voltada ao público infantil: "Os pais devem [...] impor limites, para que os filhos cresçam e se tornem consumistas conscientes $^{2 \prime \prime}$ (SEIDE, 2016, p. 51, grifos no original).

Cumpre ressaltar que o número alto de frequência de inadequações lexicais na amostra de redações pode ser relacionado ao contexto no qual elas foram solicitadas e avaliadas. Elas são resultados de uma intervenção pedagógica na qual foram contemplados, como objetos de ensino, a importância do uso das conjunções e da construção de cadeia anafórica para a construção da argumentatividade e da coesão textual (SCHNEIDERT, 2013; PALUDO, 2014; SELLA et al., 2016) , não tendo sido abordada a importância da escolha lexical para a construção da coerência textual.

Além das já citadas, a pesquisa de Oliveira (2006) também apontou a inadequação vocabular em redações escolares brasileiras como a principal fonte de falhas de redação dos alunos. Sua pesquisa foi feita com base em um conjunto de 300 redações

\footnotetext{
${ }^{2}$ Nas citações a trechos de redações escolares foi mantida a grafia original do autor dos textos.
} 
de vestibulandos e alunos primeiroanistas de curso de nível superior de uma universidade pública do estado do Rio de Janeiro.

Considerando o conjunto das pesquisas ora mencionadas, percebe-se que a dificuldade de se produzir redações sem inadequações vocabulares perpassa todos os níveis de ensino, do fundamental ao ensino superior, o que motiva que se questione o motivo pelo qual isto acontece.

Oliveira defende que a recorrência deste tipo de falha está relacionada não ao fato de o professor de Língua Portuguesa não perceber as ocorrências de inadequação vocabular, mas sim à falta de uma teoria específica sobre o assunto:

O professor às vezes, sendo um usuário maduro da língua escrita, intui como inadequada determinada combinação de palavras empregada pelo aluno, mas tem dificuldade para persuadi-lo de que se trata de impropriedade, porque lhe falta uma teoria sobre propriedade vocabular (OLIVEIRA, 2006, p. 50).

A partir da hipótese de Oliveira, no segundo semestre do ano letivo de 2014, foi feito um experimento para verificar em que medida falhas relativas à escolha lexical em redação escolar são percebidas por graduandos do curso de Licenciatura em Letras, por professores recém-formados e por professores experientes, os quais também se graduaram na mesma instituição. Esse experimento consistiu na correção de uma redação escolhida do corpus de redações do projeto desenvolvido pelo Programa de PósGraduação em Letras da Unioeste e fez parte de uma oficina de correção textual ofertada na Unioeste, no campus de Marechal Cândido Rondon.

A redação escolhida foi previamente digitada e salva nos computadores do Laboratório de Idiomas da instituição. Foi feita uma breve contextualização sobre como a redação foi produzida. Então, foi solicitado que os participantes a corrigissem inserindo comentários no texto mediante a ferramenta "inserir comentários" do programa Word do Windows. Participaram da atividade dez inscritos, dos quais foi escolhido 
um representante para cada uma das seguintes categorias descritas entre parênteses : graduando A (aluno matriculado no 1. ${ }^{\circ}$ ou no $2 .^{\circ}$ ano do curso); graduando B (aluno matriculado no $3^{\circ}$. ou no $4^{\circ}$. ano do curso), Professor A (recém-formado), Professor B (professor com 4 ou mais anos de experiência).

O número de comentários, a acuidade da avaliação e a percepção dos diferentes tipos de falha progrediram conforme os anos de escolaridade e a experiência, contudo, houve subnotificação de falhas de natureza lexical por parte de todos os inscritos, além de não terem sido percebidas as falhas relativas às características do gênero discursivo (SEIDE, 2016, p. 107).

Tendo em vista estes resultados, os planos de ensino relativos aos componentes de Língua Portuguesa e de Prática de Ensino do currículo do curso que estava em vigor na época foram analisados. Os resultados mostraram que não obstante a existência de uma disciplina intitulada Lexicologia da Língua Portuguesa os alunos e os professores formados que frequentaram essas disciplinas não utilizaram a escolha lexical como critérios de correção textual na avaliação de redação realizada durante a oficina (SEIDE, 2016, p. 108-112).

Percebida esta problemática, a ementa da disciplina de Lexicologia da Língua Portuguesa foi alterada mediante acréscimo de conteúdos teóricos e proposição de atividades práticas que pudessem motivar o licenciando a perceber os erros e os acertos lexicais de uma redação escolar e incluir a escolha lexical aos critérios de textualidade propostos pela Linguística Textual a saber: coesão, coerência, informatividade, não contradição e progressão (COSTA VAL, 1993).

Cumpre esclarecer que a proposta de inclusão de um critério relacionado à escolha lexical não desconsidera o fato de o nível lexical estar presente e fazer parte dos recursos de coerência e coesão textual, mas torna este nível explícito o bastante para não passar desapercebido durante o processo de avaliação de redações escolares. Afinal, conforme constatou Antunes e as pesquisas anteriores mencionadas neste artigo 
confirmam, é preciso que o léxico seja ensinado "como componente fundamental da construção textual dos sentidos (...) falta ver o léxico como elemento de composição do texto, em suas funções de criar e sinalizar a expressão dos sentidos e intenções, os nexos de coesão, as pistas da coerência" (ANTUNES, 2001, p. 24, grifos da autora).

Por exemplo, o princípio de não contradição costuma ser visto como uma característica macro textual relacionada a como as partes de um texto devem harmonizarse entre si do ponto de vista do significado e não como um fator para o qual também é fundamental a escolha adequada dos itens lexicais como o mostra o trecho a seguir na qual a contradição entre ser consumista e ser consciente se evidencia na combinação inadequada dos itens lexicais num trecho de outra redação oriunda da mesma proposta de produção textual mencionada no começo da introdução deste artigo: “Os pais devem [...] impor limites, para que seus filhos cresçam e se tornem consumistas conscientes“ (SEIDE, 2016, p. 51, grifos no original).

As mudanças pedagógicas realizadas incluíram a criação de um módulo didático no plano de ensino da disciplina de Lexicologia da Língua Portuguesa ofertada no ano letivo de 2019. Este artigo apresenta a fundamentação teórica, a metodologia e os resultados obtidos pela aplicação desse módulo didático em sala de aula.

\section{Fundamentação teórica}

Por abordar o ensino do léxico, a pesquisa apresentada neste artigo se fundamenta na Lexicologia, ciência que se dedica ao estudo do léxico. O léxico pode ser concebido de diversas maneiras, conforme a ênfase dada a um ou mais aspectos do conjunto de palavras de uma língua e os propósitos da pesquisa que se quer desenvolver. Biderman relaciona o léxico com a cognição e enfatiza que é através dele que uma sociedade conceptualiza o mundo, havendo uma relação intrínseca entre léxico e visão de mundo (BIDERMAN, 2001, p. 198), já Martins e Zavaglia (2014) enfatizam a relação existente entre léxico e cultura e afirmam que “o léxico é o tesouro vocabular formado 
por símbolos verbais da cultura registrados no decorrer de sua história, constituindo a fisionomia de um povo" (MARTINS; ZAVAGLIA, 2014, p. 83).

Como o objetivo deste artigo é evidenciar, empiricamente, a importância do componente lexical na avaliação da correção vocabular em redações escolares, é preciso refletir sobre como se pode enfatizar a importância de se considerar a escolha lexical como critério de avaliação de redações escolares em cursos de Licenciatura em Letras, os quais são responsáveis pela formação docente inicial do professor de Língua Portuguesa no Ensino Básico.

Embora a descrição do léxico requeira um "estudo complexo de fenômenos de fonologia, morfologia, sintaxe, semântica e pragmática" (LORENTE, 2003, p. 20), seu ensino, de acordo com as prescrições pedagógicas em vigor no Brasil (HINTZE; SEIDE, 2015; SEIDE; VESCOVI; COTTICA, 2016) se centra na reflexão sobre o uso da língua e na adoção do texto e do gênero discursivo como objetos de ensino.

No que tange o ensino do léxico no nível textual nas escolas brasileiras, é frequente a utilização dos pressupostos e dos resultados de pesquisas oriundos da Linguística Textual. Na perspectiva da textualidade, o léxico é visto como um elemento coesivo, isto é, "como elemento da composição do texto, em suas funções de criar e sinalizar a expressão dos sentidos e intenções, os nexos de coesão, as pistas da coerência" (ANTUNES, 2012, p. 24). Em consonância com este ponto de vista, a proposta de ensino de Antunes está centrada nos recursos de textualização conseguidos mediante a utilização de palavras hiperônimas, sinônimas, antônimas, palavras-valise, entre outras. Ainda que dê conta dos recursos lexicais de coesão textual, essa abordagem de ensino parece não abranger os diferentes tipos de inadequação vocabular observados em redações escolares e assim categorizados por Oliveira:

a) expressão idiomática com substituição de uma das unidades lexicais por outra ou outro tipo de modificação

b) neologismos comunicamente não adequados, sejam bem ou mal bem formados do ponto de vista morfológico 
c) item lexical incompatível com o tema ou o gênero do texto

d) escolha lexical que conflita com a orientação argumentativa do texto seja por ser positiva ou negativa demais

e) coocorrência de itens incompatíveis entre si seja no nível do sintagma, seja no nível da oração

f) itens lexicais que suscitam, no texto, "inexatidão com redundância

g) registro não admitido pelo gênero do texto, seja por ser formal, seja por ser informal

h) item lexical utilizado por "atração paronímia

i) item lexical vago por ser "uma palavra com baixa densidade semântica". (OLIVEIRA, 2006, p. 51).

Outro aspecto não enfatizado por essa abordagem é a utilização de unidades lexicais fraseológicas as quais têm um papel importante na construção textual. A relação entre a escolha lexical com o registro e a temática do texto (a qual quando mal constituída resulta nos tipos c, d e g descritos por Oliveira), bem como a contribuição das unidades fraseológicas para construção textual são levadas em consideração pela Abordagem Lexical (doravante AL) proposta por Lewis (2002) a qual foi criada, em princípio, para o ensino de língua inglesa a estrangeiros, mas que pode ser utilizada com proveito em aulas de português como língua materna (SEIDE; DURÃO, 2015).

A concepção de abordagem proposta por Lewis é, essencialmente, pedagógica pois integra "pressupostos teóricos e práticos que abrangem tanto o currículo quanto a metodologia [e] fornece princípios com os quais se decide que tipos de conteúdo e de procedimentos são adequados"3 (LEWIS, 1992, p. 2, trad. nossa).

Com relação aos conteúdos contemplados pela AL, são enfatizados os modos pelos quais as palavras são usadas em bloco formando unidades convencionais que variam de acordo com o tema, o registro e o tipo do texto abordado, entendendo-se, por textos, tanto o texto escrito propriamente dito quanto textos e enunciados orais. Assim, comparando-se a frase "Os pais devem ficar de olho onde as crianças acessam

\footnotetext{
${ }^{3}$ An approach is an integrated set of theoretical and practical beliefs, embodying both syllabus and method (...) An approach provides principles to decide what kind of content and what sorts of procedures are appropriate.
} 
os conteúdos" com a frase "Os pais devem ficar alertas e verificar que conteúdos e por quais sites são acessados pelas crianças" (SEIDE, 2016, p. 53), percebe-se que o bloco "ficar de olho" se distingue do bloco "ficar alertas" por seu registro, coloquial o primeiro, e formal o segundo. Em ambas as frases, há o uso do bloco "acessar conteúdos" o qual relaciona-se com o uso da tecnologia. Outro exemplo de blocos convencionais são os seguintes "praticar esportes", "cometer suicídio/crime/infração", "ser preconceituoso" e "ter atitudes preconceituosas".

Conforme mostra a análise de um conjunto de redações elaboradas por alunos de ensino médio de uma escola pública de Quatro Pontes, produzidas no decorrer de uma atividade extensionista desenvolvida por professores do Colegiado de Letras do campus de Marechal Cândido Rondon da Unioeste (SEIDE, 2016), às vezes, as redações apresentam falhas decorrentes do uso de blocos de palavras mal formados, como é o caso das frases "Preconceito quando é cometido pode até dar cadeia para o preconceituoso" e "Fazendo com que o leitor, se for praticante do preconceito (...)"(SEIDE, 2016, p. 50, grifos no original). Nas redações escolares, também há casos de blocos bem formados como em "(...) a pessoa que sofre bullying pode até (...) cometer suicídio" e "Os negros viviam sendo maltratados e trabalhavam sob condições precária". (SEIDE, 2016, p. 50, grifos no original).

Com relação à metodologia de ensino e os pressupostos teórico-práticos da AL, eles se baseiam numa concepção reflexiva de aprendizagem:

A aprendizagem é essencialmente provisória e cíclica, baseada na repetição infinita do ciclo Observar $(\mathrm{O})$ - Hipotetizar $(\mathrm{H})$ - e Experimen$\operatorname{tar}(\mathrm{E})$. O paradigma O-H-E de aprendizagem é claramente distinto do equivocado paradigma A-E-P [Apresentar-Exercitar - Produzir] que ainda influencia o ensino de línguas ${ }^{4}$ (LEWIS, 1993, p. 56, trad. nossa).

\footnotetext{
${ }^{4}$ Learning is essentially provisional and cyclical, based on endlessly repeating the cycle Observer $(\mathrm{O})$ Hypothesize $(\mathrm{H})$ - Experiment $(\mathrm{E})$. This O-H-E learning paradigm contrast sharply with the misguided P-P-P [Present- Practice- Produce] paradigm which still influences language teaching.
} 
Durante a atividade extensionista já aludida, a abordagem lexical aplicada à produção textual em língua materna foi experimentada. Desta experiência de intervenção pedagógica resultou uma sugestão de sequência didática (SEIDE, 2016, p. 5051). Entre os procedimentos metodológicos descritos na sequência, um deles foi selecionado como objeto de ensino e objetivo do módulo sobre o uso da AL na avaliação de textos escolares ofertado na disciplina de Lexicologia da Língua Portuguesa, a saber: a correção coletiva das redações produzidas pelo professor de modo a chamar a atenção dos alunos "para a existência de blocos de palavras, tanto os bem formados, quanto os mal formados" (SEIDE, 2016, p. 61).

As seções seguintes descrevem as metodologias utilizadas para a elaboração do módulo didático, sua aplicação e a análise dos resultados obtidos. Cumpre ressaltar que, durante todo este processo, levou-se em consideração o princípio de incerteza descrito por Lewis nos seguintes termos:

Aulas bem planejadas e inclusive bem realizadas não garantem um bom aprendizado. Aceitar a incerteza como parte de seus princípios, fará com que o professor tenha uma atitude mais paciente e tolerante perante os problemas dos alunos, e também o desejo de auxiliar os alunos em seus esforços para conseguir aprender ${ }^{5}$ (LEWIS, 1993, p. 33-34, trad. nossa).

Tendo em vista que o uso inadequado de blocos de palavras ou o uso de blocos malformados também são fonte de inadequação vocabular, também fizeram parte da fundamentação teórica utilizada os tipos de inadequação vocabular descritos por Oliveira (2006, p. 51), especialmente aqueles decorrentes “da substituição de palavras em expressões idiomáticas”, "da incompatibilidade entre a palavra escolhida e a temática

\footnotetext{
${ }^{5}$ Well -planned, and even well executed lessons cannot guarantee good learning. Accepting uncertainty as part of your mind-set develops patience, tolerance of learner's problems, a willingness to support them as they struggle with the learning process.
} 
ou gênero do texto", "do conflito entre a natureza pejorativa ou melhorativa das escolhas lexicais e a orientação argumentativa do texto" e do "emprego do vocabulário informal em situações formais e vice-versa (registro inadequado)".

\section{Metodologia}

Nesta seção, são apresentados os procedimentos metodológicos utilizados: (1) para elaboração, organização e aplicação do módulo didático na disciplina, no ano letivo de 2019, (2) para a geração e quantificação dos dados a partir da elaboração de uma amostra de trabalhos escritos pelas alunas da disciplina.

O módulo didático consistiu em uma etapa expositiva intercalada com exercícios breves e duas atividades de avaliação escrita de uma redação escolar por parte das alunas.

Na etapa mais expositiva do módulo, foi apresentado e aplicado o material didático elaborado para a ação extensionista já referida (SEIDE, 2016) pela docente, o qual complementou a aula com uma exposição sobre a Abordagem Lexical (SEIDE; DURÃO, 2015). No mesmo dia letivo, estava prevista mais uma aula geminada da disciplina. Após o intervalo, as alunas receberam uma página impressa com uma proposta de redação e uma redação escrita por um dos participantes da atividade extensionista (ver anexo 1) e foram solicitadas a avaliarem a redação. Na semana seguinte, o docente da disciplina apresentou uma avaliação completa da redação na qual foram enfatizadas as falhas e virtudes textuais decorrentes do uso do léxico e deu instruções sobre como seria feita uma das atividades avaliativas da disciplina. Essa atividade avaliativa consistiu na elaboração, em ambiente extraclasse, de um resumo do texto teórico abordado em sala de aula e na avaliação escrita de outra redação escolar produzida durante a atividade extensionista (ver anexo 2). Para sua elaboração, foi dado um prazo de uma semana e duas aulas geminadas. Nessas aulas, caso tivessem elaborado 
um esboço, as alunas poderiam passar o trabalho a limpo, neste caso deveriam, obrigatoriamente, anexar o esboço ao trabalho.

A turma em que foi feito o experimento conta com 25 alunas; considerando-se o desempenho na atividade de avaliação de redação escolar (a qual abrangeu além do aspecto lexical, os critérios de textualidade a adequação ao gênero discursivo solicitado bem como as habilidades de localizar, descrever e justificar os erros e os acertos encontrados), foi construída uma amostra representativa da turma: após classificação dos trabalhos escritos em três estratos, muito bom, bom e insatisfatório e consideração dos resultados da turma como um todo foram escolhidas 5 alunas: 1 com desempenho muito bom, 2 com desempenho bom e 2 com desempenho insatisfatório.

Para mensuração da avaliação proposta pelas alunas da amostra, foram apontados, explicitados e quantificados os comentários positivos ou negativos sobre os blocos de palavras utilizados nas redações (ver anexo 3). Tendo em vista que enquanto, para a redação 1, 14 comentários poderiam ser feitos sobre o assunto e, para redação 2,12 , optou-se por fazer um cálculo porcentual para se saber em que medida o uso das palavras por bloco nas redações foi avaliado pelas alunas. Os resultados obtidos são descritos e analisados na seção a seguir.

\section{Resultados}

Conforme mostra os resultados da tabela 1, as alunas 1 e 5 progrediram na percepção e na análise dos blocos de palavras presentes nas redações escolares. Enquanto não houve mudança significativa na avaliação da aluna 3, as alunas 2 e 5 avaliaram melhor a redação 1. Provavelmente, o desempenho superior verificado na avaliação da redação 1 está relacionado ao impacto imediato da primeira parte do módulo aplicada no mesmo dia, enquanto o desempenho insatisfatório na avaliação da redação 2, 
no que diz respeito à percepção dos blocos, pode ser relacionado ao fato de essas alunas terem sido as únicas que não anexaram nenhum anexo à avaliação da redação 02, o que indica não ter havido uma preparação prévia por parte delas.

Mesmo assim, fazendo a média de todas as porcentagens da redação 1 com todas as porcentagens relativas à redação 2, percebe-se que, na última atividade, quase dobrou a percepção da utilização de blocos de palavras (bem ou mal formados): de 19,8\% na redação 1 para 31,8\% na redação 2. Quando são subtraídos os dados das alunas que não se prepararam previamente, os dados indicam os seguintes resultados: 26,14\% na redação 1 e 53\% na redação 2 .

Tabela 1 - Síntese dos resultados: percentual de percepção adequada de blocos de palavras nas redações escolares.

\begin{tabular}{l|c|c} 
alunas & redação 1 & redação 2 \\
\hline ALUNA 1 & $7,14 \%$ & $42 \%$ \\
\hline ALUNA 2 & $14,28 \%$ & Zero \\
\hline ALUNA 3 & $57 \%$ & $42 \%$ \\
\hline ALUNA 4 & $5,88 \%$ & zero \\
\hline ALUNA 5 & 14,28\% & $75 \%$ \\
\multicolumn{2}{c}{ Fonte: elaboração própria. }
\end{tabular}

O progresso das alunas na avaliação das redações escolares a partir do léxico, não se restringiu à quantidade de fenômenos observados, além de os acertos terem sido mais notados na redação 2, também houve mais ocorrências de comentários resolutivos e estratégicos. Por exemplo, a Aluna 2 e Aluna 5, logo depois de indicarem ocorrência de blocos mal formados, sugerem soluções para estas inadequações vocabulares:

ALUNA 2: (...) “o ideal deveria ser <<agressão verbal $>>$ (..) e $<<$ praticantes de atos de preconceito $>$.....)".

ALUNA 5 "Pagar com a mesma moeda” poderia ser substituído pelo verbo retribuir, por exemplo. 
Outra observação importante relaciona-se ao progresso na percepção de que, conforme mostrara Oliveira (2006), a inadequação lexical pode ocorrer por fruto de escolhas que não combinam com o registro requerido pelo gênero discursivo em tela, como bem perceberam algumas das alunas da amostra quando afirmaram

ALUNA 5 "Nas linhas 6 e 7, "fazer justiça com as próprias mãos" e "pagar com a mesma moeda" são coocorrências na língua portuguesa. As chamadas expressões idiomáticas são blocos de palavras bem formados, porém, não adequados ao domínio social, isto é, à variação formal da língua.

ALUNA 3 Ainda "fazer justiça com as próprias mãos" é um bloco muito utilizado na oralidade - Como este bloco não estava entre aspas, isso nos mostra que a esfera oral e a norma culta não está sendo $100 \%$ monitorado pelo SEIDE de forma consciente.

Os resultados ora apresentados e analisados decorreram da comparação de desempenho em duas atividades de avaliação de redação escolar feitas por 5 alunas que representam o desempenho da totalidade de alunas da turma. Eles mostram que a aplicação do módulo didático foi capaz de aumentar a percepção e a avaliação do uso de blocos de palavras em redações escolares por parte dessas alunas, futuras professoras de línguas.

A influência positiva do módulo didático fica ainda mais evidente quando se compara a percepção de fenômenos de ordem lexical por parte da participante da oficina de 2014 que mais os percebeu com a aluna da turma que também mais se destacou neste quesito: enquanto a primeira percebeu $40 \%$ dos fenômenos desta natureza, a segunda teve uma percepção mais acurada que correspondeu a 75\% das ocorrências.

\section{Considerações Finais}


O ponto de partida da experiência pedagógica descrita neste artigo foi a percepção e o diagnóstico de uma problemática: a alta incidência de inadequação vocabular em redações escolares do Ensino Básico ao primeiro ano do ensino superior. Essa problemática nacional foi analisada localmente, mediante análise do processo avaliativo de redações escolares realizado numa oficina ofertada em 2014 para alunos e ex-alunos de um curso de Licenciatura em Letras da região oeste do Paraná e dos planos de ensino do currículo do curso em vigor na época.

Enquanto a análise do processo avaliativo revelou que as falhas redacionais de natureza lexical eram subnotificadas, a análise curricular do curso realizada em 2016 indicou que a adequação vocabular não fazia parte dos critérios de correção textual de redações escolares ensinados nas disciplinas de Linguística Textual, de Prática de Ensino e de Lexicologia da Língua Portuguesa.

Descrita a problemática do curso, foi criado um módulo didático o qual foi incluído na disciplina de Lexicologia da Língua Portuguesa ofertada no quarto ano do curso analisado em 2019. Trata-se de um módulo didático voltado a motivar os alunos da licenciatura a levarem em consideração o componente lexical no processo de correção textual de redações escolares. Esse módulo foi elaborado com base na Abordagem Lexical proposta por Lewis (2002) e na pesquisa prévia de Oliveira (2006) sobre os tipos e causas de inadequação vocabular.

A análise de uma amostra representativa de avaliações de redações escolares produzidas pelos alunos ao longo do módulo evidenciou sua eficácia pedagógica uma vez que resultou numa maior percepção de fenômenos lexicais na correção de redações escolares.

Os resultados alcançados evidenciam a adequação do uso da Abordagem Lexical no ensino do componente lexical como critério de avaliação escolares. Indicam, também, a importância de implementação de propostas para um ensino mais vigoroso do léxico nas aulas de Língua Portuguesa como língua materna mediante criação e 
aplicação de ferramentas pedagógicas que forneçam subsídios teóricos e práticos para que professores de língua portuguesa em formação inicial possam se dedicar ao ensino do léxico em seu futuro fazer docente.

\section{Referências Bibliográficas}

ANTUNES, I. Território das palavras: estudo do léxico em sala de aula. São Paulo: Parábola, 2012.

ATORRESI, A. et alii. Escritura. Un estudio de las habilidades de los estudiantes de América Latina y el Caribe. Documento fomentado pelo OREALC/ UNESCO e LLECE. Productora Gráfica Andres: Santiago, Chile, 2010.

COSTA VAL, M. da G. Redação e Textualidade. São Paulo: Martins Fontes, 1993.

HINTZE A. C.; SEIDE, M. S. O ensino do léxico na disciplina de português língua materna no ensino fundamental brasileiro. Linguagem \& Ensino, vol.18, n. 2, Pelotas, RS, p. 403-422, jul-dez, 2015.

OLIVEIRA, H. F. de. Ensino do Léxico: um problema de adequação vocabular. Revista Matraga, no. 19, Rio de Janeiro, UERJ, p. 50-68, jul.-dez., 2006.

LEWIS, M. Implementing the Lexical Approach. Putting Theory into Practice. Boston: Language Teaching Publications, 2002.

LORENTE, M. A Lexicologia como ponto de encontro entre a gramática e a semântica. In: ISQUERDO, A.P, KRIEGER, M. G. (org.). As ciências do léxico. Lexicologia, Lexicografia, Terminologia, vol. II. Campo Grande-MS: Editora UFMS, 2003. p. 19-30.

MARTINS, S. de C.; ZAVAGLIA, C. Léxico e cores: as expressões cromáticas contribuindo para a ampliação lexical. Revista Trama, vol.10, no. 20, p. 83 -96, 2014.

PALUDO, E. I. Presença de anáforas em textos produzidos por aluno do nono ano de uma escola pública do Paraná: uma amostra de progressão textual. 2013 [dissertação de mestrado]. Universidade Estadual do Oeste do Paraná, PPGL, Cascavel, PR, 2013.

SCHNEIDER, G. T. A condução argumentativa produzida por articuladores na produção textual de alunos no ensino fundamental. 2013 [dissertação de mestrado]. Universidade Estadual do Oeste do Paraná. PPGL, Cascavel, PR, 2013. 
SEIDE, M. S.; DURÃO, A. B. de A. B. A abordagem Lexical no Ensino de Língua Portuguesa como Língua Materna. Revista GTLex, v. 1, n.1, p. 11-32, 2015. DOI: https://doi.org/10.14393/Lex1-v1n1a2015-2

SEIDE, M. S.; DURÃO, A. B. de A. B. A correção de textos escolares na formação docente inicial. In: SELLA, A. F.; RODRIGUES, R. H., COSTA-HÜBES, T. da C. (org.). Contextos escolares de fronteira: resultados de pesquisas interinstitucionais. Edunioeste/Eduel, Cascavel/Londrina, 2016. p. 93-120.

SEIDE, M. S. Inadequação vocabular em redações escolares brasileiras. Confluência, Rio de Janeiro, v.47, p.157-171, 2015.

SEIDE, M. S.; VESCOVI, P.; COTTICA, A. M. A Base Nacional Comum Curricular e o Estudo do Léxico nos cursos de Licenciatura em Letras. Revista GTLex, v. 1, n. 2, p. 237-256, 5 set. 2016. DOI : https://doi.org/10.14393/Lex2-v1n2a2016-1

SELLA, A. F.; ROMAN, E. C.; OLIVEIRA, E. G. de. Conjunções coordenativas e subordinativas no processo de refacção em produção escrita de aluno do ensino fundamental. In: SELLA, A. F.; RODRIGUES, R. H., COSTA-HÜBES, T. da C. (org.). Contextos escolares de fronteira: resultados de pesquisas interinstitucionais. Cascavel -PR: Edunioste, Londrina: Eduel, 2016. p. 81-92.

\section{Anexo 1}

\section{DESCRIÇÃO DO GÊNERO COMENTÁRIO INTERPRETATIVO-CRÍTICO}

- O comentário interpretativo-crítico apresenta título.

- $1^{\underline{o}}$ Momento: leitura pessoal do texto/imagem $\rightarrow$ síntese e identificação das ideias presentes no texto, como o autor aborda o tema e expõe sua problemática, qual seu esquema de raciocínio, etc. - Nesta primeira parte, o autor do comentário deverá retomar/situar o leitor sobre o texto/matéria/charge que ele está interpretando/analisando.

- 2o Momento: formulação de juízo crítico $\rightarrow$ concorda-se ou discorda-se do ponto de vista do autor (com justificativa $\rightarrow$ argumentação), se seu posicionamento é original, relevante ou traz contribuições, se sua argumentação é sólida e coerente, etc.

\section{PROPOSTA DE PRODUÇÃO TEXTUAL}

Redija um COMENTÁRIO INTERPRETATIVO CRÍTICO, para ser publicado no blog de Alexandre Beck, sobre a tirinha a seguir. Lembre-se de que você deverá apresentá-la e interpretá-la criticamente. 

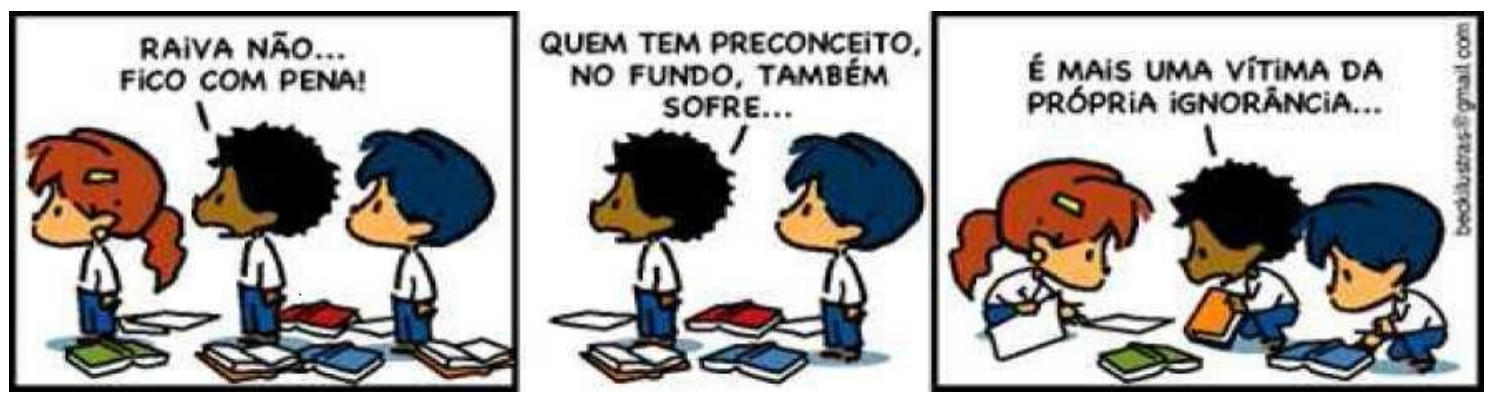

(Alexandre Beck.) Disponível em https://www.facebook.com/tirasarmandinho?fref=ts, acesso em 15/09/2014).

Redação

\begin{tabular}{|l|l|}
\hline 1 & \multicolumn{1}{|c|}{ Preconceito } \\
\hline 2 & Muitas pessoas ainda tem preconceito em pleno no século 21, se não acabarmos com \\
\hline 3 & o preconceito muitas pessoas ainda irão sofrer. Preconceito quando é cometido_pode \\
\hline 4 & até dar cadeia para o preconceituoso, quando uma pessoa é preconceituosa, ela está \\
\hline 5 & deixando de conhecer novas pessoas. O preconceito é uma coisa antiga que não \\
\hline 6 & deveria existir nos dias atuais pois o mundo está tão avançado que não poderia \\
\hline 7 & $\begin{array}{l}\text { acontecer mais. Quando uma pessoa é preconceituosa, ela está sendo ignorante com si } \\
\text { mesma. }\end{array}$ \\
\hline 8 & Não é apenas o preconceito por uma pessoa ser negra, mas também por ter \\
\hline 9 & costumes diferentes dos seus. Quando uma pessoa gosta, de algo e outra não ela pode \\
\hline 10 & sofrer preconceito, ou quando é mais gorda ou mais magra que as pessoas ao seu redor, \\
\hline 11 & ou até por ser de uma classe social baixa. Se não deixarmos o preconceito de lado, ele \\
\hline 12 & nunca deixará de existir. Nas redes sociais o preconceito ainda é maior, principalmente \\
\hline 13 & no Facebook. Quando uma pessoa sobre preconceito muitas vezes seguidas, dizemos \\
\hline 15 & que ela está sofrendo bullying, a pessoa que sofre bullying pode até entrar em depressão \\
\hline 16 & e até cometer suícidio. \\
\hline
\end{tabular}

\section{Anexo 2}

\section{ATIVIDADES PREPARATÓRIAS PARA A 1ª. PROVA DE LEXICOLOGIA}

1) Escreva uma síntese do artigo A Abordagem Lexical no ensino de língua portuguesa como língua materna (SEIDE, DURÃO, 2015) no qual sejam cumpridas as tarefas abaixo descritas de modo a formar um texto dissertativo, com título e, que tenha, no corpo do texto, no mínimo, 500 palavras.

a) Informar em que consiste a Abordagem Lexical

b) Explicar o que justifica sua utilização em aulas de Língua Portuguesa como língua materna.

c) Descrever o módulo criado para o uso desta metodologia em aulas de língua portuguesa

d) Finalizar o texto, dando e justificando sua opinião pessoal sobre o módulo proposto e/ou sobre a utilização a Abordagem Lexical em aulas de Língua Portuguesa como língua materna. 
2.A redação abaixo foi escrita por um aluno de escola pública como resposta à proposta 2 de redação para o vestibular da Unioeste. Escreva um texto que pontue os erros e os acertos dessa redação, localizando-os e analisando-os tendo em vista: o gênero discursivo solicitado, a adequação vocabular e os critérios de textualidade (coesão, coerência, informatividade e progressão temática).

\section{PROPOSTA DE PRODUÇÃO TEXTUAL}

Redija um COMENTÁRIO INTERPRETATIVO CRÍTICO, para ser publicado no blog de Alexandre Beck, sobre a tirinha a seguir. Lembre-se de que você deverá apresentá-la e interpretá-la criticamente.
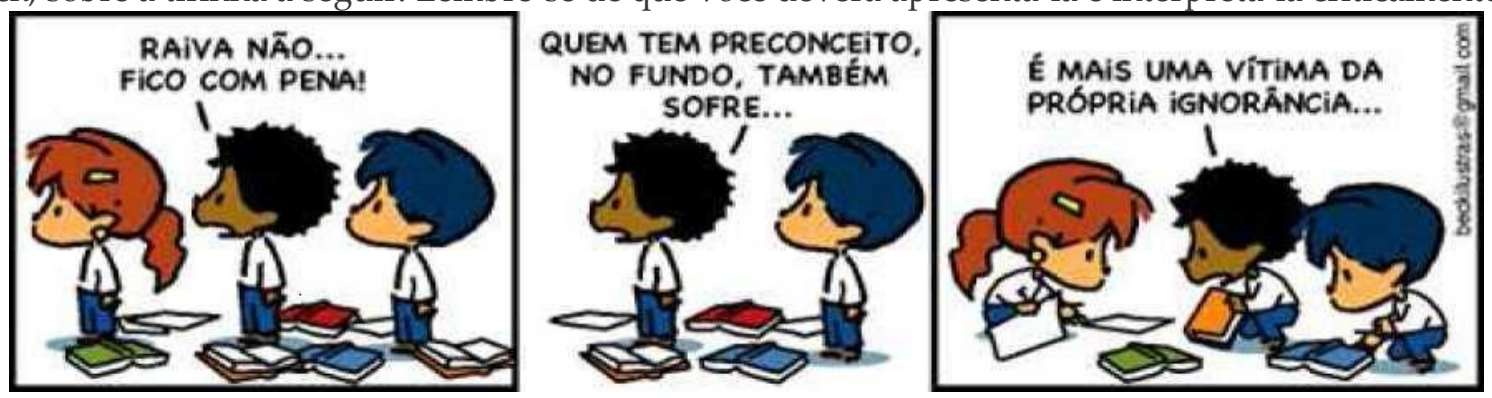

(Alexandre Beck.) Disponível em https://www.facebook.com/tirasarmandinho?fref=ts, acesso em 15/09/2014).

\section{Redação 2}

1. Acredito que a tirinha de Alexandre Beck está correta quando. afirma que o agressor é.a 2;vítima.da própria ignorância. Pessoas que não conseguem lidar com outras pessoas só pelo.fato de 3;serem negras, brancas, gays, lésbicas, ricas, pobres, magras ou gordas, etc.

4. Na tira a personagem negra representa quem sofre e não mostra importância para as ofenças, 5.representa quem sabe que o agressor, tanto verbal quanto físico, este é quem.precisa de ajuda. Nem 6.todas as pessoas que sofrem preconceito, ficam caladas, não tentam.fazer a justiça com as próprias 7.mãos. Algumas pessoas tentam "pagar com a mesma moeda",.causando assim, a desordem e 8.prejudicando ainda mais a visão que o agressor tem sobre a.pessoa.

9.. Tendo em vista que o objetivo do SEIDE era concientizar, mais uma vez, os leitores, 10.percebemos que ele o fez com sucesso, fazendo com que o leitor, se este for praticante do 11.preconceito, deixe de fazer, de praticar esse ato tão ridículo e desnecessário.

\section{Anexo 3}

Avaliação do uso de blocos de palavras na redação 1

Blocos bem formados: 12 blocos sendo 10 blocos diferentes

(1) tem preconceito

(2) acabamos com o preconceito

(3) deixando de conhecer novas pessoas

(4) é preconceituosa

(5) gostar de algo

(6) pode sofrer preconceito

(7) ser de uma classe social mais baixa

(8) sofre preconceito - repetição do bloco 6 - 


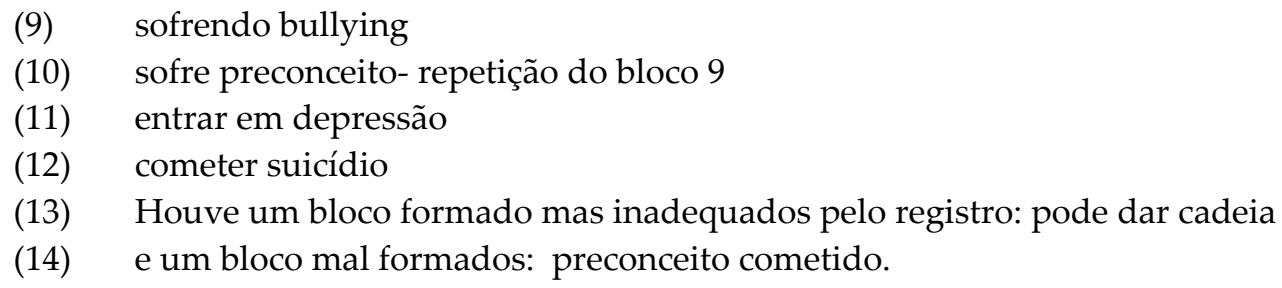

\section{Avaliação de blocos de palavras na redação 2}

blocos bem formados

(1) conseguem lidar com outras pessoas

(2) pelo fato de serem

(3) alguém representar alguém

(4) sofrer preconceito

(5) fazer justiça com as próprias mãos (inadequação de registro)

(6) "pagar com a mesma moeda" (inadequação de registro)

(7) conscientizar alguém

(8) causando a desordem

blocos mal formados

(9) não mostra importância para as ofensas

(10) agressor verbal

(11) agressor físico

(12) praticante de preconceito 